University of Wollongong

Research Online

Faculty of Engineering and Information

Faculty of Engineering and Information

Sciences - Papers: Part A

Sciences

2017

\title{
Stir casting process for manufacture of Al-SiC composites
}

Shahin Soltani

Sahand University of Technology

R Azari Khosroshahi

Sahand University of Technology

R Taherzadeh Mousavian

Sahand University of Technology, Islamic Azad University

Zhengyi Jiang

University of Wollongong, jiang@uow.edu.au

Alireza Fadavi Boostani

University of Wollongong, afb496@uowmail.edu.au

See next page for additional authors

Follow this and additional works at: https://ro.uow.edu.au/eispapers

Part of the Engineering Commons, and the Science and Technology Studies Commons

Research Online is the open access institutional repository for the University of Wollongong. For further information contact the UOW Library: research-pubs@uow.edu.au 


\title{
Stir casting process for manufacture of Al-SiC composites
}

\author{
Abstract \\ Stir casting is an economical process for the fabrication of aluminum matrix composites. There are many \\ parameters in this process, which affect the final microstructure and mechanical properties of the \\ composites. In this study, micron-sized SiC particles were used as reinforcement to fabricate Al- $3 \mathrm{wt} \% \mathrm{SiC}$ \\ composites at two casting temperatures $\left(680\right.$ and $\left.850^{\circ} \mathrm{C}\right)$ and stirring periods ( 2 and $\left.6 \mathrm{~min}\right)$. Factors of \\ reaction at matrix/ceramic interface, porosity, ceramic incorporation, and agglomeration of the particles \\ were evaluated by scanning electron microscope (SEM) and high-resolution transition electron \\ microscope (HRTEM) studies. From microstructural characterizations, it is concluded that the shorter \\ stirring period is required for ceramic incorporation to achieve metal/ceramic bonding at the interface. \\ The higher stirring temperature $\left(850^{\circ} \mathrm{C}\right)$ also leads to improved ceramic incorporation. In some cases, \\ shrinkage porosity and intensive formation of AI4C3 at the metal/ceramic interface are also observed. \\ Finally, the mechanical properties of the composites were evaluated, and their relation with the \\ corresponding microstructure and processing parameters of the composites was discussed.

\section{Disciplines} \\ Engineering | Science and Technology Studies

\section{Publication Details} \\ Soltani, S., Azari Khosroshahi, R., Mousavian, R. Taherzadeh., Jiang, Z., Fadavi Boostani, A. \& Brabazon, D. \\ (2017). Stir casting process for manufacture of Al-SiC composites. Rare Metals, 36 (7), 581-590.
}

\section{Authors}

Shahin Soltani, R Azari Khosroshahi, R Taherzadeh Mousavian, Zhengyi Jiang, Alireza Fadavi Boostani, and D Brabazon 


\section{Stir casting process for manufacture of Al-SiC composites}

S. Soltani ${ }^{1}$, R. Azari Khosroshahi ${ }^{1}$, R. Taherzadeh Mousavian ${ }^{1}{ }^{*}$, Z. Y. Jiang ${ }^{2}$, A. Fadavi Boostani ${ }^{2}$ D. Brabazon ${ }^{3}$

1: Faculty of Materials Engineering, Sahand University of Technology, Tabriz, Iran 2: School of Mechanical, Materials and Mechatronic Engineering, University of Wollongong, NSW 2522, Australia

3: Advanced Processing Technology Research Centre, School of Mechanical \& Manufacturing Engineering, Dublin City University, Dublin 9, Ireland Email: rtaher1898@gmail.com, $\underline{r}$ taherzadeh@sut.ac.ir

Tel: +98 919959 1160, Fax: +984133441676

\section{Abstract}

Stir casting is an economical process for fabricating aluminium matrix composites. There are many parameters in this process which affect the final microstructure and mechanical properties of the composites. In this study, micron-sized SiC particles were used as a reinforcement, and $\mathrm{Al}-3 \mathrm{wt}$ \% SiC composites were fabricated at two casting temperatures (680 and $850^{\circ} \mathrm{C}$ ) and stirring times ( 2 and $6 \mathrm{~min}$ ). Factors of reaction at matrix/ceramic interface, porosity, ceramic incorporation, and agglomeration of the particles were evaluated with SEM and HRTEM. From results of microstructural characterizations, it was concluded that a minimum stirring time is mandatory for ceramic incorporation and for achieving a desired metal/ceramic bonding at the interface. Also, it was found that a higher stirring temperature $\left(850{ }^{\circ} \mathrm{C}\right)$ would lead to an improved ceramic incorporation, while shrinkage porosity and intensive formation of $\mathrm{Al}_{4} \mathrm{C}_{3}$ at the metal/ceramic interface were observed. The mechanical properties of the composites were also evaluated and their relation with the corresponding microstructure of the composites was discussed.

Keywords: Aluminum matrix composite, Microstructure, Mechanical properties, stir casting. 


\section{1- Introduction}

Aluminum metal matrix composites (AMMCs) have gained significant attention in recent years. This is primarily due to their lightweight, low coefficient of thermal expansion (CTE), machinability, and improved mechanical properties, such as increased $0.2 \%$ yield stress (YS), ultimate tensile stress (UTS), and hardness. Due to these advantages, they are used in aerospace industries (airframe and aerospace components), automobile industries (engine pistons), and electronic components [1-11].

Stir casting (vortex technique) is generally accepted commercially as a low-cost method for fabricating AMMCs. Its advantages lie in its simplicity, flexibility, and applicability to large volume production. This process is the most economical of all the available routes for AMMCs production, and it allows very large-sized components to be fabricated. However, methods of achieving the following in stir casting most be considered: (i) no adverse chemical reaction between the reinforcement material and matrix alloy, (ii) no or very low porosity in the cast AMMCs, (iii) wettability between the two main phases, and (iv) achieving a uniform distribution of the reinforcement material. Wettability and reactivity determine the quality of the bonding between the constituents and, thereby, greatly affect the final properties of the composite material [12-19].

The addition of alloying elements can modify the matrix metal alloy by producing a transient layer between the particles and the liquid matrix. This transient layer has a low wetting angle, decreases the surface tension of the liquid, and surrounds the particles with a structure that is similar to both the particle and the matrix alloy $[3,12,14,15]$. Our previous study [3] indicated 
that $\mathrm{Mg}$ is the best metal among $\mathrm{Ca}, \mathrm{Ti}, \mathrm{Zn}, \mathrm{Si}$, and $\mathrm{Zr}$ for increasing the incorporation \% of micron-sized SiC particles by molten pure aluminum.

In this study, micron sized-SiC particles were used as reinforcement of pure aluminum to fabricate as-cast aluminum matrix composite, and Mg addition (1 wt. \%) was aided to improve the wettability and incorporation \% of ceramic particles. The main aim of this study is to lessen the defects of stir casting method and improve the quality of the fabricated composites. Therefore, factors of reaction at matrix/ceramic interface, porosity, ceramic incorporation, and agglomeration of particles were evaluated. The mechanical properties of the composites were also investigated and their relation with the corresponding microstructures was discussed.

\section{2- Experimental Procedures}

Aluminum ingot with 99.8 in wt. \% commercial purity was used as a matrix. The chemical composition of the used ingot obtained using a M5000 optical emission spectrometer is given in Table 1.

Table 1

Chemical composition of the pure aluminum used in this study.

Micron-sized SiC particles with an average particle size of $80 \mu \mathrm{m}$ and $99.9 \%$ purity were supplied (Shanghai Dinghan Chemical Co., Ltd. China) as the reinforcement of metal matrix composite. The morphology of the silicon carbide particles used in this study is shown in the SEM micrographs in Fig. 1.

Fig. 1. The morphology of SiC particles which were used as reinforcement.

In order to fabricate the composites, one gram of reinforcement SiC powder was encapsulated carefully in an aluminum foil packet for insertion into the molten aluminium in order to 
fabricate a composite with $3 \mathrm{wt}$. \% SiC as reinforcement. These powders were pre-heated at $350{ }^{\circ} \mathrm{C}$ for $4 \mathrm{~h}$ before the casting process for removing the moisture and impurities. The pure aluminum was heated to various temperatures of 680 and $850{ }^{\circ} \mathrm{C}$ within a bottom-pouring furnace. A pre-heated graphite stirrer was placed below the surface of melt and rotated with a speed of $500 \mathrm{rpm}$ and simultaneously argon with a high purity was used as a protective shroudon the melt surface. Fig. 2 shows the schematic of the vortex casting set-up used for casting process. The composite slurry was poured into a low-carbon steel mould. As mentioned, $1 \% \mathrm{Mg}$ scrap (mass fraction) was added to the melt to increase the wettability between the matrix and the reinforcements.

Mg acts like a surfactant power that obtains the oxygen. The magnesium reacts with alumina to form $\mathrm{MgAl}_{2} \mathrm{O}_{4}$ spinel at the interface $\mathrm{Al} / \mathrm{SiC}$, as shown by the following reactions [20-23]:

$3 \mathrm{Mg}(\mathrm{l})+\mathrm{Al}_{2} \mathrm{O}_{3}(\mathrm{~s}) \rightarrow \mathrm{MgO}(\mathrm{s})+2 \mathrm{Al}(\mathrm{l})$

$3 \mathrm{Mg}(\mathrm{l})+4 \mathrm{Al}_{2} \mathrm{O}_{3}(\mathrm{~s}) \rightarrow 3 \mathrm{MgAl}_{2} \mathrm{O}_{4}(\mathrm{~s})+2 \mathrm{Al}(\mathrm{l})$

Fig. 2. The schematic of stir casting set-up used for fabrication of composites.

In summary, three samples were fabricated in this study, which their fabrication routes are shown in Table 2. Generally, a lower stirring time is beneficial due to three important reasons. First, a lower casting duration is economically preferred. Second, the reaction occurrence between matrix and reinforcement might need a long exposure time, meaning that this detrimental phenomenon might be avoided using a lower amount of stirring time. Third, higher casting duration may lead to entrance of a higher amount of porosity after solidification [24]. Therefore, sample $S_{1}$ was designed in this study to investigate if further stirring after particle feeding is necessary or not. As shown in Table 2, the process of particle feeding during casting 
process was lasted for $2 \mathrm{~min}$ for all the samples. However, irrespective of sample $\mathrm{S}_{1}$, the stirring was continued for extra 4 min after this 2 min time of feeding process. In fact, the ceramic particles for sample $S_{1}$ have no time after incorporation to be stirred and distributed in molten metal.

\section{Table 2}

\section{Characteristics of the samples fabricated in this study.}

The specimens were prepared for metallographic examinations using 220-320-500-1000 mesh emery papers, followed by polishing with diamond paste $1 \mu \mathrm{m}$. Microscopic methods were used to study the composite structure and fracture surface using two kinds of scanning electron microscopes (SEM, Cam Scan Mv2300, equipped with EDAX analysis and SEM, KYKY-EM3200), and an optical microscope (OM). A high-resolution transmission electron microscope (HRTEM, Philips CM200) at an accelerating voltage of $200 \mathrm{kV}$ was also used to study the reaction occurrence at the interface of aluminum matrix and $\mathrm{SiC}$ particles.

Microhardness tests were conducted according to ASTM E384 using an applied load of $50 \mathrm{~g}$ for a $15 \mathrm{~s}$ duration. At least ten measurements were taken from fabricated samples. Tensile specimens were also prepared from the as cast composites. All of the tensile tests were performed at room temperature using an Instron type-testing machine operating at a constant rate of crosshead displacement, with an initial strain rate of $2 \times 10^{-3} \mathrm{~s}^{-1}$. The $0.2 \%$ proof strength (interpreted as the measurable YS), UTS and ductility (\% elongation to break) were measured and averaged over 3 test samples. For a fair judgment about mechanical properties, the density of the samples was measured using Archimedes' principle. Distilled water was used as the 
immersion fluid. Theoretical density was calculated by rule of mixture and compared with the measured densities.

In order to determine the onset reaction temperature between pure aluminum and SiC powders, differential scanning calorimetry (DSC) analysis (Netzsch STA 409, Germany) was used. For this purpose, a same weight of aluminum and $\mathrm{SiC}$ powders were mixed for $30 \mathrm{~min}$ using a low-energy ball-mill to make a suitable contact between them and break the possible oxide layer on the aluminum surface, and the milled powders were then heated from 25 to 800 ${ }^{\circ} \mathrm{C}$ with the heating rate of $10^{\circ} \mathrm{C} /$ min using pure argon atmosphere and alumina crucible.

\section{3- Results and discussion}

\section{3-1- SEM and OM studies of the composite microstructures}

Figs. 3-5 show the SEM images of the fabricated samples $S_{1}$ to $S_{3}$, respectively. Fig. 3a shows the microstructure of sample $S_{1}$, in which just after ceramic feeding for 2 min, the stirring process was stopped. Some points could be drawn from this figure: first, the amount of ceramic particles seems to be insignificant for this sample, meaning that further stirring might be necessary for the powders to be well entered into the melt and a required bonding forms between particles and melt leading to the embed of the ceramics with a good distribution. Our visual examinations indicated that a large fraction of the powders were still remained on the surface of the melt and adhered to the crucible wall. Second, the presence of gas pores is also evident in this microstructure. It has been reported that the source of porosity in cast MMCs were originated from gas entrapment during stirring, water vapor $\left(\mathrm{H}_{2} \mathrm{O}\right)$ on the surface of the ceramic particles, hydrogen evolution, air bubbles entering the slurry as an air envelope to the

reinforcement particles, and shrinkage during solidification process [12]. Due to pre-heating of 
the SiC powders at $350^{\circ} \mathrm{C}$ no water vapor could be present on the ceramic surfaces and also hydrogen evolution seems not to be considerably occurred at $680^{\circ} \mathrm{C}$, a very close temperature to the melting point of pure aluminum. It seems that gas entrapment was occurred specially in this range of temperature, in which the viscosity of the melt is very high. In fact, due to a high viscosity of the melt, the slurry cannot highly release the entrapped gases. This affects the gas escape and thereby increases the porosity level. Third, solidification shrinkage was occurred in just one part (see Fig. 3a), and it seems that this defect is not highly evident at this temperature, while air gap between the agglomerated particles could be observed in Fig. $3 a$. Fig. $3 b$ shows the phenomenon of particle detachment from the matrix after polishing process to prepare the samples for microstructural characterization. This matter indicated that the bonding between them is not adequate enough in this sample. Due to a direct contact between molten aluminum and $\mathrm{SiC}$ particles, $\mathrm{Al}_{4} \mathrm{C}_{3}$ could be formed the interface [25-28]. It has been reported [26] that a layer of aluminum carbide $\left(\mathrm{Al}_{4} \mathrm{C}_{3}\right)$ was found to increase the YS and UTS, work hardening rate, and changes the fracture pattern from one involving interfacial decohesion to one where particle breakage was dominant. Although the stirring temperature is $680^{\circ} \mathrm{C}$ for the sample $\mathrm{S}_{1}$, however, it seems that no bonding reaction might be occurred for this sample, which this matter was investigated in the next section.

Fig. 3. SEM image of smaple $S_{1}$ after stir casting, (a) low-magnification, (b) high-magnification. Fig. 4a shows the microstructure of sample $S_{2}$ casted at $680{ }^{\circ} \mathrm{C}$, and the stirring for four extra minutes was applied after particle feeding. The presence of gas pore and solidification shrinkage was shown using yellow-colored circle and red-colored rectangles, respectively. It is important to note that a lower amount of gas pores could be seen in this sample, meaning that 
further stirring and turbulence in the slurry could help the entrapped gases to escape from the melt, while 6 min stirring at $680^{\circ} \mathrm{C}$ might attract further hydrogen gases from the environment. This shows that gas entrapment is more dominant in respect to hydrogen evolution at this temperature. As it can be seen, the amount of ceramic particles is considerable for this sample, meaning that mechanical stirring is a real factor for incorporation improvement of ceramics by molten metal. Also, it is concluded from this microstructure that stirring time could not affect the formation of shrinkage solidification and this unwanted phenomenon mainly influenced by temperature of stirring and mould in $\mathrm{Al}-\mathrm{SiC}$ composites. The most important point which could be drawn from Fig. $4 \mathrm{~b}$ is the formation of a relative defect-free interface between matrix and reinforcement. The ceramic particles seems to be well adhered to the matrix and no detachment of particles from the matrix could be seen during sample preparation for microstructural study. This shows that the stirring time is a very important parameter for achieving a desired interface. Fig. $4 c$ shows that the entrance of air between the particles could also be seen in the microstructure of sample $S_{2}$. In fact, it seems that mechanical stirring could not avoid the formation of agglomerated particles at $680^{\circ} \mathrm{C}$ and a large fraction of porosity in this sample might be emanated from the air gap between the ceramic particles.

\section{Fig. 4. SEM image of smaple $S_{2}$ after stir casting, (a) low-magnification, (b and c) high-magnifications.}

Fig. 5 a shows the microstructure of sample $S_{3}$ casted at $850{ }^{\circ} \mathrm{C}$, in which the ceramic particles were stirred for $6 \mathrm{~min}$. As it can be seen, considerable amounts of ceramic particles were incorporated into the matrix at this temperature. It has been reported that $\mathrm{SiC}$ particles has a higher wettability by molten aluminum at higher temperatures [15]. This image confirms that sample $S_{3}$ contains the highest amount of ceramic particles. Another important matter is the 
presence of round-shape gas pores which have the average diameter less than $10 \mu \mathrm{m}$. An intensive attraction of environmental gases occurred for this sample at $850{ }^{\circ} \mathrm{C}$ for aluminum alloys $[29,30]$ and it seems that these round-shape small pores are not related to gas entrapment due to very low viscosity of the melt [31, 32]. Like the other samples, agglomeration of ceramic particles could be observed for this sample. However, the distribution of ceramic particles seems to be better for this sample in respect to the samples $S_{1}$ and $S_{2}$. From Fig. 5a, it seems that particles were well bonded to the matrix. However, Fig. 5b shows the considerable occurrence of particle detachment from the matrix. From the reaction occurrence point-view, it might be concluded that this should be due to the formation brittle $\mathrm{Al}_{4} \mathrm{C}_{3}$ compound, while Fig. 5c indicated that intensive shrinkages were taken place for this samples during solidification and this shrinkage highly affects the detachment of these particles. As it can be seen from Fig. 5c, even a crack was formed as a result sudden reduction of temperature from $850{ }^{\circ} \mathrm{C}$ to room temperature (no pre-heating was applied for the mould). These matters indicated that sample $S_{3}$ contains these detrimental defects in some parts. Fig. $5 c$ also demonstrates that air gap between the particles was also formed for this sample.

Fig. 5. SEM image of smaple $S_{3}$ after stir casting, (a) low-magnification, (b and c) high-magnification. In summary, Table 3 compared the charateristics of as-cast samples as regards four factors of reaction at interface, ceramic amount, ceramic agglomeration, and matrix-ceramic bonding. This Table was desinged based on the SEM and HRTEM anlysis.

\section{Table 3}

The summary of obtained results for the composite samples. 
Line EDAX microanalysis (see Fig. 6) was used to evaluate the chemical characterization around a ceramic particle in sample $S_{3}$. As shown in Fig. 6 , the presence of $\mathrm{Mg}$ is evident, meaning that this element not only presents at the $\mathrm{Al} / \mathrm{SiC}$ interface, but also its trace could be found in the matrix of aluminum with a same intensity. In fact, it could be deduced that Al-Mg alloy was fabricated as a result of adding $1 \mathrm{wt} . \% \mathrm{Mg}$ chips to the vortex.

\section{Fig. 6. EDAX anlysis around a ceramic particle in sample $\mathrm{S}_{3}$.}

OM analysis was used in this study to compare the grain size of the matrix alloy after composite solidification of samples $S_{2}$ and $S_{3}$. One important point could be obtained from Figs. $7 \mathrm{a}$ and $7 \mathrm{~b}$. As a result of solidification from a higher temperature of $850^{\circ} \mathrm{C}$ in respect to $680{ }^{\circ} \mathrm{C}$, a higher value of grain size was formed for sample $S_{2}$ (see Fig. 7a) rather than sample $S_{3}$ (see Fig. $7 b$ ). This would affect the mechanical properties based on Hall-Petch equation [33]. In fact, a more quick solidification could further avoid the growth of aluminum grains.

Fig. 7. OM study of as-cast samples (a) $S_{2}$, (b) $S_{3}$.

\section{3-2- Reaction between aluminum matrix and SiC particles}

It was reported $[27,34]$ that from 657 to $827^{\circ} \mathrm{C}$, SiC interacts with aluminum via a dissolutionprecipitation process. This mechanism involves the migration of carbon atoms from places where the SiC surface is in direct contact with the aluminum to the growing faces of $\mathrm{Al}_{4} \mathrm{C}_{3}$ crystals located at or close to the aluminum-SiC interface. The $\mathrm{Al}_{4} \mathrm{C}_{3}$ brittle compound has detrimental influences within the composite and reduces the strength and ductility, and also it reacts with liquid water or with moisture in the ambient, debilitating even more the composite [35]. $\mathrm{Al}_{4} \mathrm{C}_{3}$ would be formed based on Eq. 1 [36]:

$3 \mathrm{SiC}+4 \mathrm{Al}=3 \mathrm{Si}+\mathrm{Al}_{4} \mathrm{C}_{3}$ 
The reaction is thermodynamically possible because the standard free energy change for this reaction is negetive and $\mathrm{Al}_{4} \mathrm{C}_{3}$ and $\mathrm{Si}$ are the two major interfacial reaction products $[28,34,36]$. As mentioned, the migration of carbon atoms (exchange of atoms) is involved in a chemical reaction, leading to wettability and bonding improvement. Therefore, it seems that $\mathrm{Al}_{4} \mathrm{C}_{3}$ formation to a low extent is suitable for required bonding between $\mathrm{SiC}$ and aluminum [37]. However, intensive reaction between $\mathrm{Al}$ and $\mathrm{SiC}$ due to long exposure time or very high casting temperature which leads to the formation of a more thick layer of $\mathrm{Al}_{4} \mathrm{C}_{3}$ might not to be suitable for AMMCs [37].

Fig. 8 shows the thermal analysis of the ball-milled Al-SiC mixture. As it can be seen, just after the melting of aluminum at about $670{ }^{\circ} \mathrm{C}$, an exothermic trend could be observed, which corresponds to the occurrence of a reaction between $\mathrm{Al}$ and SiC, leading to a large release of heat. It seems that reaction was occurred completely at about $720^{\circ} \mathrm{C}$. This figure indicates that Al and SiC tend to react with each other just after melting of the aluminum.

Fig. 8. DSC anlysis of Al-SiC powder mixture.

In order to evaluate the reaction occurrence between $\mathrm{Al}$ and $\mathrm{SiC}$ and observe the boding of $\mathrm{SiC}$ with aluminum matrix, HRTEM analysis was used for all the samples. Fig. 9a shows the nanostructure of sample $S_{1}$. As it can be seen, a relative clean interface was formed between crystalline SiC and aluminum matrix, and no trace of $\mathrm{Al}_{4} \mathrm{C}_{3}$ could be observed at or near the interface, meaning that 2 min stirring at $680^{\circ} \mathrm{C}$ is not high enough for the migration of carbon atoms and formation a suitable bond between $\mathrm{Al}$ and SiC particles. It is very important to note that aluminum foils contain $\mathrm{SiC}$ particles were not simultaneously entered into the melt and therefore, some of the particles had less than 2 min time for stirring and boding to the matrix. It 
has been reported [38] that $\mathrm{Al}_{4} \mathrm{C}_{3}$ appears as needle or slice like on the interface toward the matrix side in HRTEM micrograph and no trace of $\mathrm{Al}_{4} \mathrm{C}_{3}$ could be detected in this sample. Fig. $9 \mathrm{~b}$ shows the nanostructure of sample $S_{2}$, in which particles were exposed to the molten aluminum for 6 min during stirring. A very good physical bonding seems to be formed for this sample between $\mathrm{Al}$ and crystalline $\mathrm{SiC}$ and after too long characterization, needle like $\mathrm{Al}_{4} \mathrm{C}_{3}$ phase was detected with a different orientation growth from the crystalline plane orientations of silicon carbide. However, it should be noted that the size of this needle-like phase seems to be less than $8 \mathrm{~nm}$ in height. Therefore, it is concluded that this phase could be fabricated after $6 \mathrm{~min}$ stirring at $680{ }^{\circ} \mathrm{C}$. During detection of $\mathrm{Al}_{4} \mathrm{C}_{3}$ for sample $\mathrm{S}_{3}$ at the interface using a very high magnification, it was found that exposure of $\mathrm{SiC}$ with molten aluminum at $850{ }^{\circ} \mathrm{C}$ highly affects the formation and growth of this phase even just after $6 \mathrm{~min}$ stirring. Fig. 9c shows the nanostructure of sample $\mathrm{S}_{3}$. As it can be seen, $\mathrm{Al}_{4} \mathrm{C}_{3}$ with a height of about $120 \mathrm{~nm}$ was simply detected at the Al/SiC interface which selected area diffraction (SAD) pattern of the corresponding phase confirms its formation with a crystalline structure, which it is not clear if this large sized phase could adversely affect the mechanical properties.

Fig. 9. HRTEM study of as-cast samples (a) $S_{1},(b) S_{2}$, and (c) $S_{3}$.

\section{3-3- Mechanical properties and fractography analysis}

Tensile and Vickers microhardness tests were conducted in order to evaluate the effects of porosity content, ceramic particle, formation of $\mathrm{Al}_{4} \mathrm{C}_{3}$, and matrix grain size on the mechanical properties. Table 4 shows the results of relative densities of the samples.

\section{Table 4}

The relative densities of the samples. 
As it can be seen from this Table, no intensive difference in relative density could be seen between the samples. As mentioned, the type of porosity and its shape highly affect the mechanical properties, and round-shaped pores do not reduce the tensile strenght and ductility as much as edge-like pores due from stress-concentration view-point. The shrinkage porosities are not round in shape and therefore, they could lessen the bonding strength at matrix/ceramic interface and mechanical properties of the composite would be reduced if they form at the interface. The other effective parameter is the presence of ceramic particles. Due to the difference of SiC and Al alloy shrinkage (the thermal expansion coefficient of SiC is about $4 \times 10^{-6}$ $\mathrm{C}^{-1}$, the thermal expansion coefficient of Al alloy is greater than $20 \times 10^{-6} \mathrm{C}^{-1}$ ), internal stress will increase in the composite materials, leading to the formation of dislocations around the particles, which strengthens the composite [39-42]. It should be noted that if the cooling rate is too fast, then the resulting internal stress may be significant. If these stresses exceed the maximum strength of the aluminum alloy, this phase might crack [40-42].

Fig. 10 shows the results of tensile and microhardness tests. As it can be seen, the values of average microhardness were increased by increasing the amount of ceramic particles. Figs. 3- 5 indicated that samples $S_{1}$ to $S_{3}$ have a higher amount of ceramic particles, respectively. This means that interface quality seems not to be highly effective in this regard. As it can be observed, the YS and UTS values of sample $S_{2}$ are higher than that of sample $S_{1}$ due a stronger interface and the presence of a higher amount of ceramic particles. However, this trend could not be seen for sample $S_{3}$, in which lower amounts of YS and UTS were obtained in respect to sample $S_{2}$. This means that the considerable formation of shrinkage porosity at the interface will be significantly reduced the strength of a composite which even has a higher amount of 
ceramic particle. However, it is not clear that the intensive formation of $\mathrm{Al}_{4} \mathrm{C}_{3}$ (see Fig. 9c) could adversely affect the bonding and strength of the composite. Care should be taken that sample $S_{3}$ has a relatively lower grain size in respect to sample $S_{2}$ (see Fig. 7). However, this slight difference in grain size could not make this sample to be more stronger than that of sample $S_{2}$.

Fig. 10 also shows the values of ductility for the samples, in which a higher amount of ductility was obtained for samples $S_{1}$ containing lower ceramic particles. It could be concluded that the presence of ceramic particles and formation of shrinkage porosities around the particles are two important factors in this regard, in which sample $S_{3}$ has a lower ductility in respect to sample $S_{2}$.

Fig. 10. Mechanical properties of the as-cast samples.

The relationship between the particle strength and particle/ matrix interfacial bonding strength is the critical criterion to determine the fracture mode of the composites during deformation. If the particle/matrix interfacial bonding strength is high, particle fracture usually happens during deformation. On the other hand, if the particle/matrix interfacial bonding strength is weak, decohesion between the SiC particles and the aluminum matrix will occur prior to the particle fracture [43-49]. Fig. 11a shows a particle fracture mode for sample $S_{2}$ with a strong bonding. The presence of dimples in the matrix is also evident for this sample. It seems that matrix deformation was taken place and at last, the ceramic was fractured after matrix deformation. The micrograph in Fig. 11b clearly shows that particle debonding has taken place at particlematrix interface. The presence of cracks around the SiC particles is also evident for this sample. This image shows that debonding of SiC particles was taken place before deformation of matrix, although no facet could be seen in the matrix, meaning that the matrix has a ductile nature. 


\section{Fig. 11. SEM study of fracture surfaces of samples (a) $S_{2}$, and (b) $S_{3}$.}

\section{Conclusions}

Micron-sized SiC particles were incorporated into a melt of pure aluminum with the aid of $\mathrm{Mg}$ addition as wetting agent to fabricate aluminum matrix composite. Two casting temperatures and stirring times were applied to focus on the ceramic particle incorporation, porosity formation, agglomeration of ceramic particles, interfacial reactions between $\mathrm{Al}$ and SiC. The following results could be drawn from this study:

1- No suitable bonding would be obtained at the metal/ceramic interface for the stirring time of 2 min, meaning that a minimum stirring time is necessary for ceramic particles to be well in contact with the melt and make a strong interface.

2- Formation of $\mathrm{Al}_{4} \mathrm{C}_{3}$ would lead to a better $\mathrm{Al} / \mathrm{SiC}$ bonding at $680{ }^{\circ} \mathrm{C}$, while its intensive formation at $850^{\circ} \mathrm{C}$ might reduce the mechanical properties of the composite.

3- A higher stirring temperature would lead to a further incorporation of ceramic particles into the molten pure aluminum with an improved distribution.

4- Agglomeration of the micron-sized SiC particles could be observed in all the samples, meaning that the stirring time and temperature and viscosity of the melt could not affect this matter.

5- Gas pores, solidification shrinkage, and air gap between the agglomerated ceramic particles are observed in the samples after stir casting, while by changing the stirring time and temperature, the type and the amount of the porosities will be changed. 
6- Detachment of ceramic particles from the matrix was observed in some areas when the ceramic particles were not stirred for a suitable time, and the composite was cooled at a high rate during solidification.

7- By using $50 \mathrm{~g}$ load for microhardness test, it was found that a sample with a higher amount of ceramic particle is harder than the other samples, while the tensile strength and ductility amounts are observed to be intensively depended on the interface of $\mathrm{Al} / \mathrm{SiC}$.

\section{References}

[1] M. Roshan, R. T. Mousavian, H. Ebrahimkhani, A. Mosleh, Journal of Mining and Metallurgy, Section B: Metallurgy, 49 (2013) 299-305.

[2] N. Valibeygloo, R.A. Khosroshahi, R.T. Mousavian, International Journal of Minerals, Metallurgy, and Materials, 20 (2013) 978-985.

[3] M. Mohammadpour, R. Azari Khosroshahi, R. T. Mousavian, D. Brabazon, Ceramics International, 40 (2014) 8323-8332.

[4] M. Mohammadpour, R.A. Khosroshahi, R.T. Mousavian, D. Brabazon, Metallurgical and Materials Transactions B, 1-8.

[5] A.F. Boostani, R.T. Mousavian, M. Roshan, K. Amini, M. Soltanpour, Majlesi Journal of Materials Engineering, 7 (2014).

[6] M. Emamy, N. Nemati, A. Heidarzadeh, Materials Science and Engineering: A, 527 (2010) 2998-3004.

[7] A. Heidarzadeh, M. Emamy, A. Rahimzadeh, R. Soufi, D.S.B. Heidary, S. Nasibi, Journal of materials engineering and performance, 23 (2014) 469-476.

[8] S. Naher, D. Brabazon, L. Looney, Journal of Materials Processing Technology, 166 (2005) 430-439.

[9] S. Naher, D. Brabazon, L. Looney, Composites Part A: Applied Science and Manufacturing, 38 (2007) 719-729.

[10] S. Tahamtan, A. Halvaee, M. Emamy, Z. Jiang, A.F. Boostani, Materials Science and Engineering: A, (2014).

[11] A. Fadavi Boostani, S. Tahamtan, Z.Y. Jiang, D. Wei, S. Yazdani, R. Azari Khosroshahi, R. T. Mousavian, J. Xu, X. Zhang, D. Gong, Composites Part A: Applied Science and Manufacturing.

[12] J. Hashim, L. Looney, M. Hashmi, Journal of Materials Processing Technology, 92 (1999) 1-7.

[13] S. Naher, D. Brabazon, L. Looney, Journal of Materials Processing Technology, 143 (2003) 567-571.

[14] J. Hashim, L. Looney, M. Hashmi, Journal of Materials Processing Technology, 119 (2001) 329-335.

[15] J. Hashim, L. Looney, M. Hashmi, Journal of Materials Processing Technology, 119 (2001) 324-328.

[16] T. Rajan, R. Pillai, B. Pai, K. Satyanarayana, P. Rohatgi, Composites Science and Technology, 67 (2007) 3369-3377.

[17] M. Surappa, Materials Science and Engineering: A, 480 (2008) 117-124.

[18] I. Ibrahim, F. Mohamed, E. Lavernia, Journal of materials science, 26 (1991) 1137-1156.

[19] T. Srivatsan, I. Ibrahim, F. Mohamed, E. Lavernia, Journal of Materials Science, 26 (1991) 5965-5978.

[20] T. Rajan, R. Pillai, B. Pai, Journal of Materials Science, 33 (1998) 3491-3503.

[21] B. Schultz, J. Ferguson, P. Rohatgi, Materials Science and Engineering: A, 530 (2011) 87-97. 
[22] K. Sukumaran, S. Pillai, R. Pillai, V. Kelukutty, B. Pai, K. Satyanarayana, K. Ravikumar, Journal of materials science, 30 (1995) 1469-1472.

[23] E. Candan, H.V. Atkinson, Y. Turen, I. Salaoru, S. Candan, Journal of the American Ceramic Society, 94 (2011) 867-874.

[24] S.B. Prabu, L. Karunamoorthy, S. Kathiresan, B. Mohan, Journal of Materials Processing Technology, 171 (2006) 268-273.

[25] A. Urena, E. Martınez, P. Rodrigo, L. Gil, Composites science and Technology, 64 (2004) 1843-1854.

[26] L. Tham, M. Gupta, L. Cheng, Acta Materialia, 49 (2001) 3243-3253.

[27] M. Yan, Z. Fan, Journal of materials science, 36 (2001) 285-295.

[28] A. Ureña, M. Escalera, L. Gil, Journal of materials science, 37 (2002) 4633-4643.

[29] R. Monroe, AFS Transactions, 113 (2005) 519-546.

[30] D. Lapham, C. Schwandt, M. Hills, R. Kumar, D. Fray, lonics, 8 (2002) 391-401.

[31] J. Yi, Y. Gao, P. Lee, H. Flower, T. Lindley, Metallurgical and Materials Transactions A, 34 (2003) 1879-1890.

[32] Q. Wang, P. Crepeau, C. Davidson, J. Griffiths, Metallurgical and Materials Transactions B, 37 (2006) 887-895.

[33] N. Hansen, Scripta Materialia, 51 (2004) 801-806.

[34] J. Viala, F. Bosselet, V. Laurent, Y. Lepetitcorps, Journal of materials science, 28 (1993) 5301-5312.

[35] M.I. Pech-Canul, Recent Trends in Processing and Degradation of Aluminum Alloys, (2011) 299-314.

[36] J.-C. Lee, J.-Y. Byun, S.-B. Park, H.-I. Lee, Acta materialia, 46 (1998) 1771-1780.

[37] S. Bao, K. TANG, A. Kvithyld, T. Engh, M. Tangstad, Transactions of Nonferrous Metals Society of China, 22 (2012) 1930-1938.

[38] H. Yang, M. Gu, W. Jiang, G. Zhang, Journal of materials science, 31 (1996) 1903-1907.

[39] Ü. Cöcen, K. Önel, Composites Science and Technology, 62 (2002) 275-282.

[40] R. Arpon, J. Molina, R. Saravanan, C. Garcia-Cordovilla, E. Louis, J. Narciso, Acta Materialia, 51 (2003) 3145-3156.

[41] T. Huber, H.-P. Degischer, G. Lefranc, T. Schmitt, Composites Science and Technology, 66 (2006) 2206-2217.

[42] N. Chawla, X. Deng, D. Schnell, Materials Science and Engineering: A, 426 (2006) 314-322.

[43] S. Tahamtan, A.F. Boostani, H. Nazemi, Journal of Alloys and Compounds, 468 (2009) 107-114.

[44] A. Fadavi Boostani, S. Tahamtan, Journal of Alloys and Compounds, 481 (2009) 220-227.

[45] A. Fadavi Boostani, S. Tahamtan, Materials \& Design, 31 (2010) 3769-3776.

[46] P. Mummery, B. Derby, Materials Science and Engineering: A, 135 (1991) 221-224.

[47] J. Lewandowski, C. Liu, W. Hunt Jr, Materials Science and Engineering: A, 107 (1989) 241-255.

[48] Z. Wang, M. Song, C. Sun, Y. He, Materials Science and Engineering: A, 528 (2011) 1131-1137.

[49] Z. Wang, M. Song, C. Sun, D. Xiao, Y. He, Materials Science and Engineering: A, 527 (2010) 65376542. 


\section{Tables Caption}

Table 1

The chemical composition of the pure aluminum used in this study.

Table 2

Characteristics of the samples fabricated in this study.

Table 3

The summary of obtained results for the composite samples.

Table 4

The relative density of the samples. 


\section{Figures Caption}

Fig. 1. The morphology of SiC particles which were used as reinforcement.

Fig. 2. The schematic of stir casting set-up used for fabrication of composites.

Fig. 3. SEM image of smaple $S_{1}$ after stir casting, (a) low-magnification, (b) high-magnification.

Fig. 4. SEM image of smaple $S_{2}$ after stir casting, (a) low-magnification, (b and c) high-magnifications.

Fig. 5. SEM image of smaple $S_{3}$ after stir casting, (a) low-magnification, (b and c) high-magnification.

Fig. 6. EDAX anlysis around a ceramic particle in sample $S_{3}$.

Fig. 7. OM study of as-cast samples (a) $S_{2},(b) S_{3}$.

Fig. 8. DSC anlysis of Al-SiC powder mixture.

Fig. 9. HRTEM study of as-cast samples (a) $S_{1}$, (b) $S_{2}$, and (c) $S_{3}$.

Fig. 10. Mechanical properties of the as-cast samples.

Fig. 11. SEM study of fracture surfaces of samples (a) $S_{2}$, and (b) $S_{3}$. 